\title{
Ultrastructure of the Normal Atrial Endocardium
}

\author{
R. A. LANNIGAN AND SALEH A. ZAKI \\ From the Department of Pathology, University of Birmingham, and the Department of Pathology,
University of Assiut, U.A.R.
}

Surgical biopsies of the heart and early needle "biopsies" at necropsy now permit ultrastructural investigations into many cardiac conditions. There are, however, very few such studies on normal human myocardium and none are available on human or animal endocardium. The commonest surgical specimens from the heart are from the left or right atrial appendages, and this material has been used to study normal structure, as a baseline for the investigation of cardiac diseases such as rheumatic heart disease and fibro-elastosis, etc. For obvious reasons, it is difficult to obtain fresh material from "normal" hearts, and specimens were selected for electron microscopy which were within normal limits on the light microscope (Lannigan, 1959).

\section{Material AND Methods}

Three left atrial appendages and three right appendages have been extensively examined. The left atrial appendages were obtained from one case of bronchial carcinoma and two cases of calcific aortic stenosis with no mitral valve disease (ages 38, 47, 61 years) and the right atrial appendages were from cases of congenital heart disease (ages 14, 24, 27 years). The specimens were collected immediately after removal and a strip of tissue a few millimetres wide was cut around the whole circumference. The strip was moistened with 1 per cent buffered osmium tetroxide, and small blocks $1 \times 1 \times 1 \mathrm{~mm}$. were cut with a razor-blade from various areas around the circumference. The blocks included endocardium and a narrow zone of myocardium. Approximately 20 blocks were taken from each specimen, fixed in 1 per cent cold buffered osmium tetroxide for 30 to 45 minutes, and after dehydration, which included treatment with 1 per cent phosphotungstic acid in alcohol, they were embedded in methacrylate and araldite.

Thick sections were cut on a Huxley ultramicrotome, and orientation of the tissue was made so that the sections passed at right angles to the endocardial surface.

Received September 2, 1965.

3E 785
Thin sections were then cut and examined on an A.E.I. E M 6 electron microscope.

For light microscopy, blocks of the whole circumference were embedded in paraffin and sections were stained with Ehrlich's hæmatoxylin and eosin, van Gieson's stain, Lawson's modification of the WeigertSheridan elastic stain, the periodic-acid Schiff reaction, and Hale's dialysed iron.

\section{RESULTS \\ Light Microscopy}

The structure of the left atrial wall has been described by Koniger (1903), Nagayo (1909), Von Glahn (1926), and Gross (1935), and the structure of the atrial appendages, which was shown to be similar to that of the atrium, was described by Waaler (1952), Lannigan (1959), and Ling, Wang, and Kuo (1959).

Two main layers can be distinguished, (i) the endocardium proper which is avascular apart from penetrating Thebesian veins and (ii) the subendocardium which contains blood vessels (Fig. 1). According to Becker (1964), the subendocardium, in contrast to the endocardium, arises embryologically in common with the myocardium. The distinction between the two layers is more evident in the early years of life (Gross, 1935). The endocardium and subendocardium of the left atrial appendage is many times thicker than that of the right.

Several layers can be distinguished in the endocardium proper: (a) an endothelial cell layer consisting of a single row of flattened endothelial cells; (b) a subendothelial layer consisting mainly of delicate collagen fibrils; and (c) an elastic layer with elastic and collagen fibres and an interrupted smooth muscle layer which is rarely seen in the right atrial appendage.

The subendocardium contains coarse elastic and 


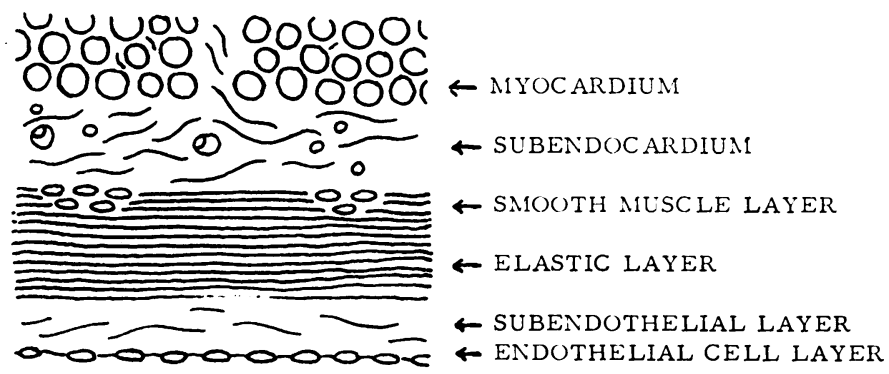

FIG. 1.-Diagrammatic representation of the normal atrial endocardium.

collagen fibres, and the main distinguishing feature is the presence of capillaries. This layer is continuous with the myocardial septa. A few isolated cells can be seen in the endocardium and subendocardium but are more frequent in the latter.

\section{Electron Microscopy}

Endocardium

(a) Endothelial cell layer. This single layer of endothelial cells faces the lumen at one side and a basement membrane at the other. In sections perpendicular to the surface the cells appear flat and are wider at the site of the nucleus (Fig. 2). The cell membrane is irregular on the side of the lumen and sometimes projects to form short villi. Close cell junctions, which are arranged in an interlocking manner, are present between adjoining cells and usually occur in the flat portion. Pinocytic vesicles, in variable numbers, and thin filaments are seen in pale cytoplasm. Other organelles include small numbers of mitochondria, very occasional lipid droplets, and variable numbers of roughsurfaced tubules of endoplasmic reticulum. Occasionally there are large vacuoles and the lining membrane is continuous with the cell membrane on either side of the cell (Fig. 3).

The finely fibrillar basement membrane underlying the endothelium separates the endothelial cells from the subendothelial layer (Fig. 2 and 3), and at the endothelial cell junctions it passes from one cell to the other.

(b) Subendothelial layer. This is a narrow layer of connective tissue devoid of elastic fibres (Fig. 3 and 4), whose main structures are collagen fibrils arranged in fibre form, being loosely dispersed in many directions. These fibrils are thin (100-250 A.U.), showing indistinct periodicity of $440-500$ A.U.; there is little variation in their diameter, and this, together with the indistinct crossbanding, frequently leads to erroneous measuring of the

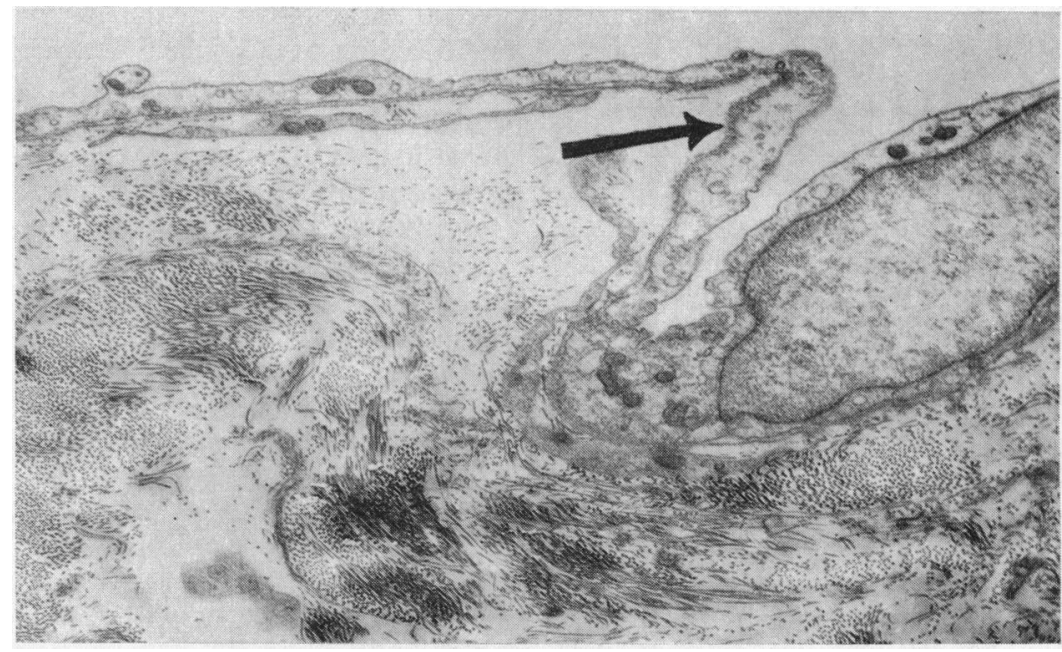

Fig. 2.-Part of the endothelial cell nucleus and a thin layer of cytoplasm. Note the fibrillary basement membrane (arrow). (Osmic-araldite $\times 6500$.) 


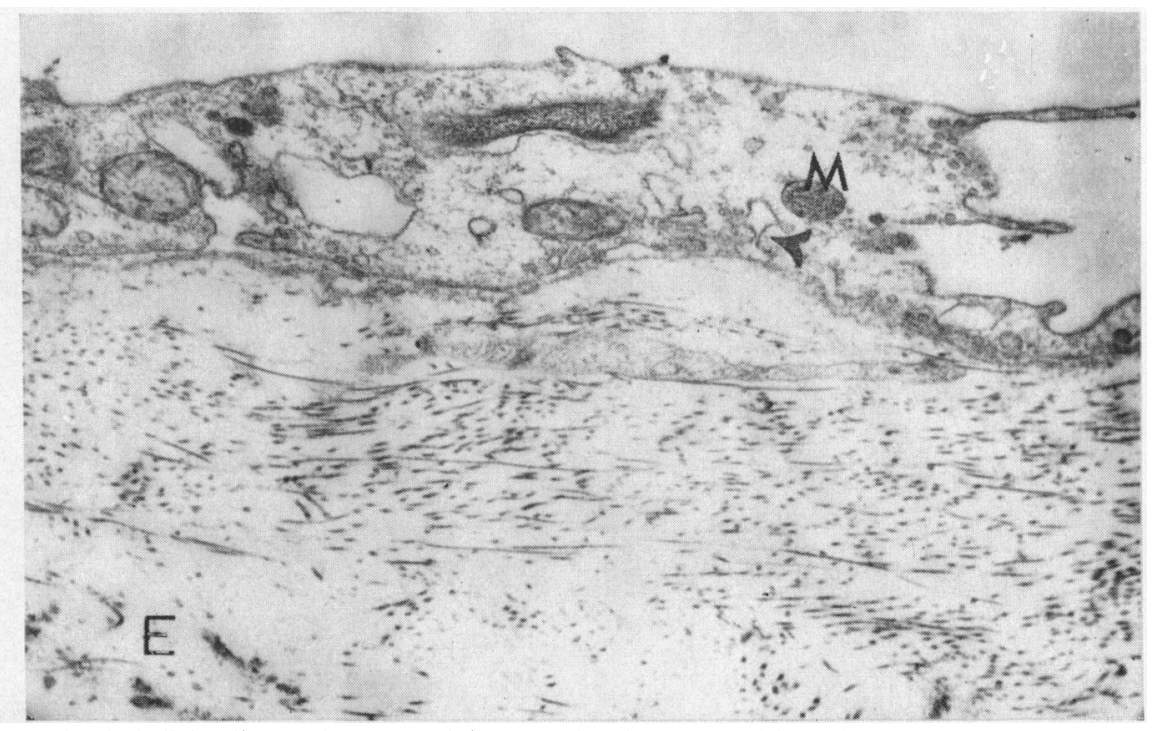

FIG. 3.-Endothelial cell cytoplasm containing occasional mitochondria $(M)$ and vesicles. Note the continuity of the lining of the vesicles and the cell membrane (arrow). The collagen fibrils in the subendothelial layer are not arranged in fibres. The beginning of the elastic layer (E) can be seen (bottom left). (Osmicaraldite $\times 19,500$.)

periodicity. If the measurement is made between main bands and sub-bands a periodicity of half the actual value may be obtained. Short thin fibrillæ showing no periodicity, which are commonly seen between recognizable collagen fibrils, and do not appear to be developing collagen filaments, usually occur in small groups and are commonly related to the basement membrane.

Cells of variable morphology are not infrequently seen in the subendothelial layer, and usually have small amounts of poorly differentiated cytoplasm and a large nucleus but no basement membrane around (Fig. 4). On rare occasions fibroblasts and areas of collagen fibrillogenesis are seen.

(c) Elastic layer. The beginning of this layer is marked by the appearance of elastic fibres (Fig. 4), which increase in size and complexity as they approach the subendocardium (Fig. 5). Tiny elastic fibres near the subendothelial layer have a dense homogeneous structure and show little variation in size. Those fibres deeper in the layer are less osmiophilic and have a fairly uniform density, the outlines being often irregular and complex in pattern. Dense lines and dots are seen in the larger elastic fibres more commonly in methacrylate-embedded material. A layer of dense fibrillary material is often found on the surfaces of the fibres, morphologically resembling the short fibrillæ which are also related to basement membrane (Fig. 5).

Collagen is usually present in the form of fibre arranged parallel to the endothelial surface. The periodic banding is more distinct and sub-periodic bands are better resolved. The diameter of the fibrils is larger than in the subendothelial layer (250-350 A.U.); the periodicity measures $450-540$ A.U., focal increases in the diameter of the fibrils being commonly noted at the main band regions. Collagen fibres contain fibrils which run parallel to, and at regular distances from each other (Fig. 6). The number of fibrils in a fibre is variable, the fibrils being of uniform thickness.

Areas of collagen fibrillogenesis are present in the neighbourhood of fibroblasts. Thin collagen fibrils showing indistinct periodicity and not arranged in an orderly fashion are present together with long thin filaments showing no periodicity (Fig. 7). The latter are occasionally beaded and appear to be developing collagen filaments.

An interrupted layer of smooth muscle cells is present in the elastic layer near to the subendocardium: these cells nearly always lie in groups several cells thick arranged in one direction with a characteristic ultrastructure. In longitudinal section they are spindle-shaped with tapering ends; and one or two nuclei are situated in the wider central portion (Fig. 8). Projections of cell membrane forming "intercellular bridges" can be seen, but no cytoplasmic continuity has been noted. The cytoplasm is dense and this results from closely packed filaments which run in the long axis of the cell. The filaments show no striation and have 


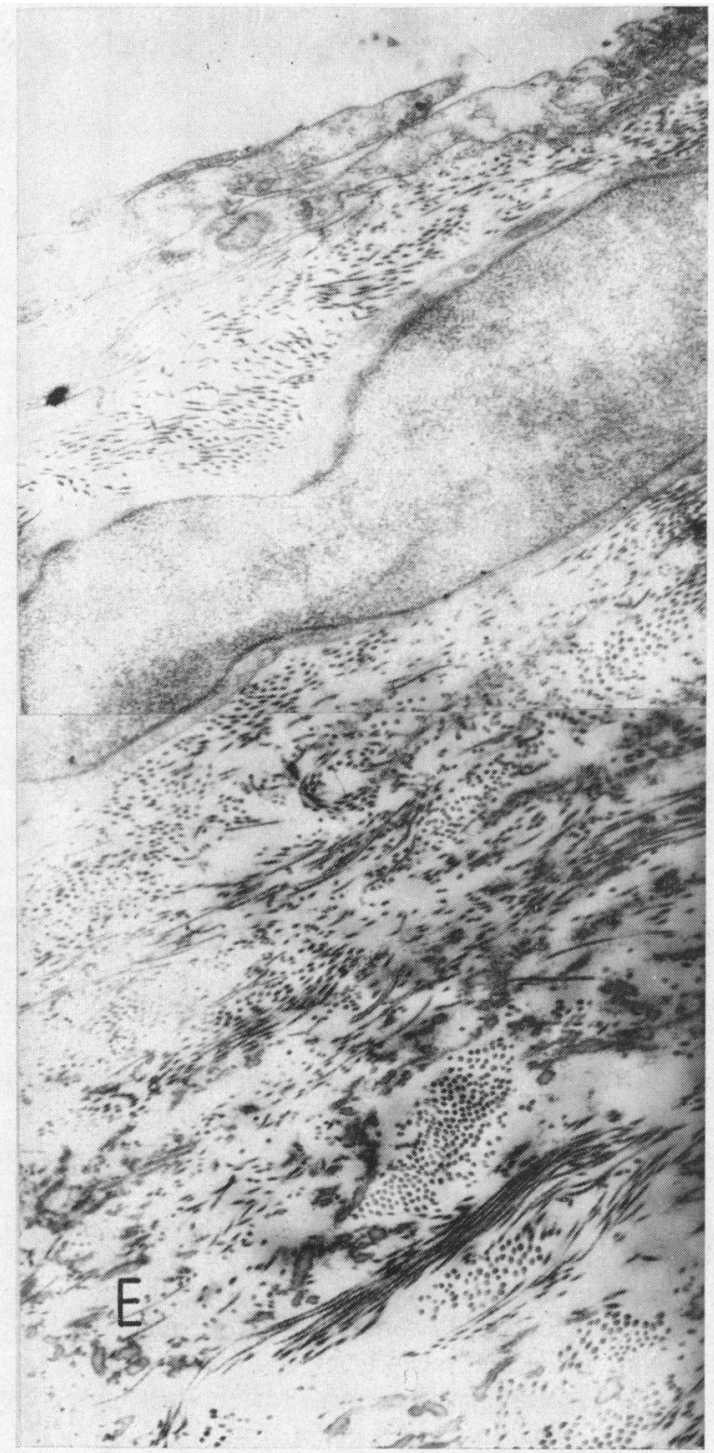

Fig. 4.-Endothelium, subendothelium, and part of the elastic layer. The cell in the subendothelial layer is an undifferentiated cell. Collagen fibres are cut in various directions. Elastic tissue is indicated $(\mathrm{E})$ (Osmic-araldite $\times 16,000$.)

characteristic oblique or longitudinal fusiform densities along their course.

Organelles are found in the perinuclear zone and in circumscribed areas between the fibrillary cytoplasm. Golgi complex membranes are present near the nuclear poles, and a few small tubular, dense, mitochondria are also found in these areas among smooth-surfaced tubules of endoplasmic reticulum.

Pinocytotic vesicles are noted near the cell membrane, and glycogen granules of variable

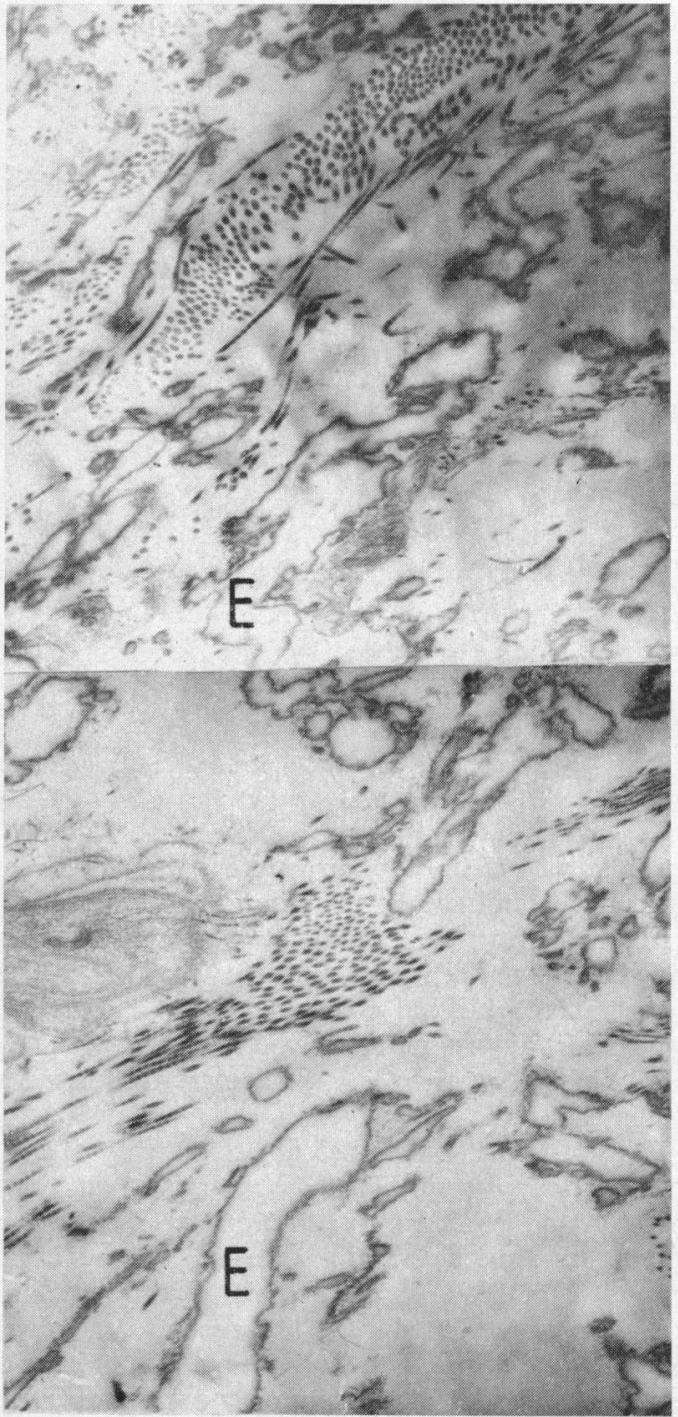

Fig. 5.-Continuation of Fig. 3 to subendocardium. Note the increasing complexity of the elastica and the increasing thickness of collagen fibres. The smooth muscle layer is not present in this area. (Osmic-araldite $\times 16,000$.)

density occur in the cytoplasm. A fibrillary basement membrane which is variable in thickness surrounds the cell membrane. There are frequently elastic fibres of small diameter between the cells and collagen fibrils.

Nerve axons may be seen within the elastic layer, occupying a position roughly in line with or close to the smooth muscle cells. Usually numerous, they are partially or completely invested by Schwann cells, and are surrounded by a thin fibrillary basement membrane. 


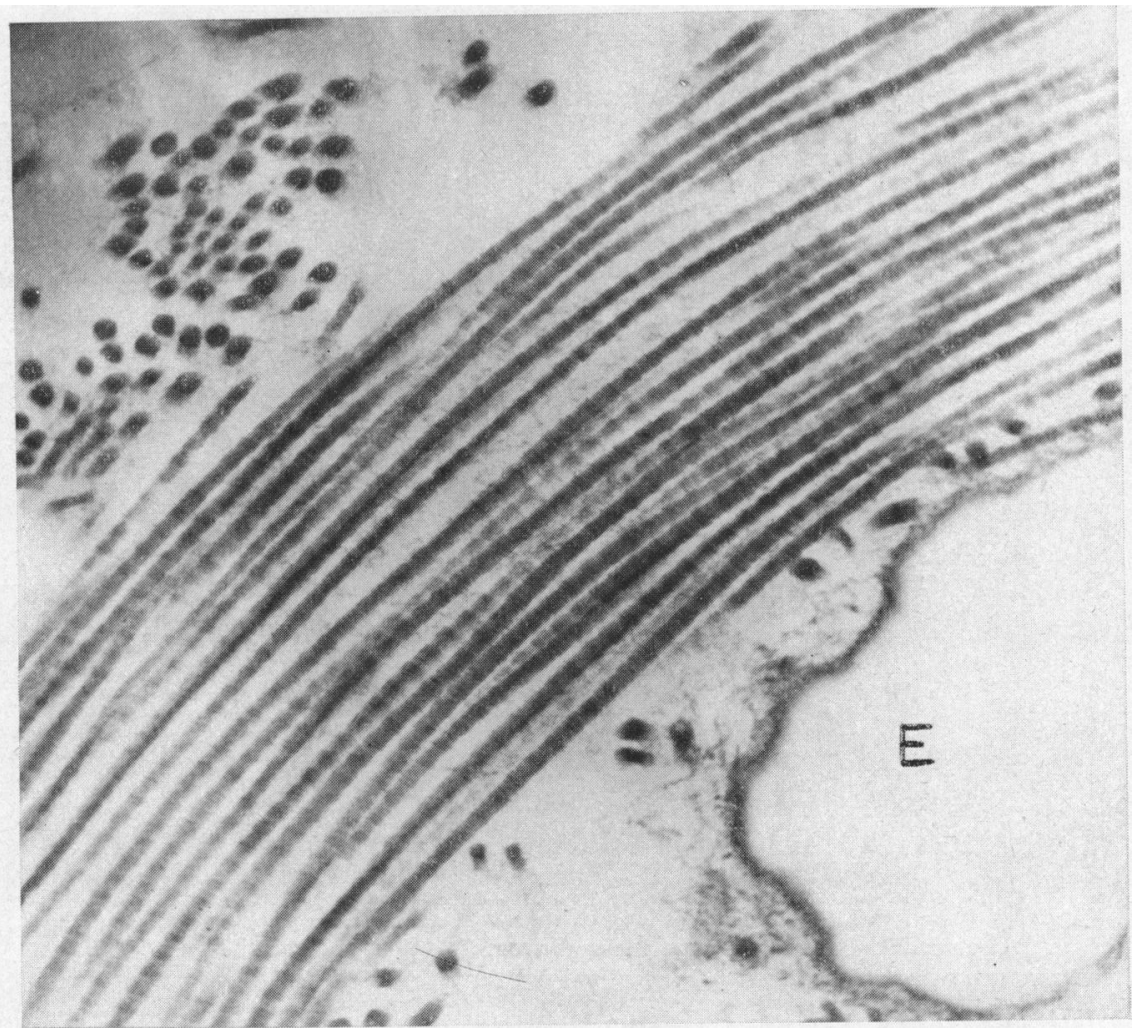

FIG. 6.-Collagen fibre and elastic fibre. Note the distinct periodicity of the collagen fibrils. Around the elastic fibre $(\mathrm{E})$ are numerous fibrillæ. (Osmic-araldite $\times 60,000$.)

Cells identified as fibroblasts, undifferentiated cells, and occasional macrophages are present; as these are more commonly found in the subendocardium, they will be described later.

\section{Subendocardium}

There is no clear-cut dividing line between the endocardium and the subendocardium, the main characteristics of which are the presence of vascular elements, mainly capillaries, and the occurrence of thick collagen and elastic fibres with wide spaces between (Fig. 5). The elastic fibres are large and complex, but immediately adjacent to the myocardium they are very small. The collagen fibres contain large numbers of fibrils of the thick type (250-450 A.U.) with periodicity 500-580 A.U., and the banding distinct. Areas of collagen fibrillogenesis are much commoner in this region, and fibroblasts are usually present in the vicinity.

Vascular elements. The majority of vessels are capillaries of various types (Fig. 9) with occasional metarterioles and arterioles; some of the capillaries are accompanied by pericytes of different size and different degree of cytoplasmic differentiation. 


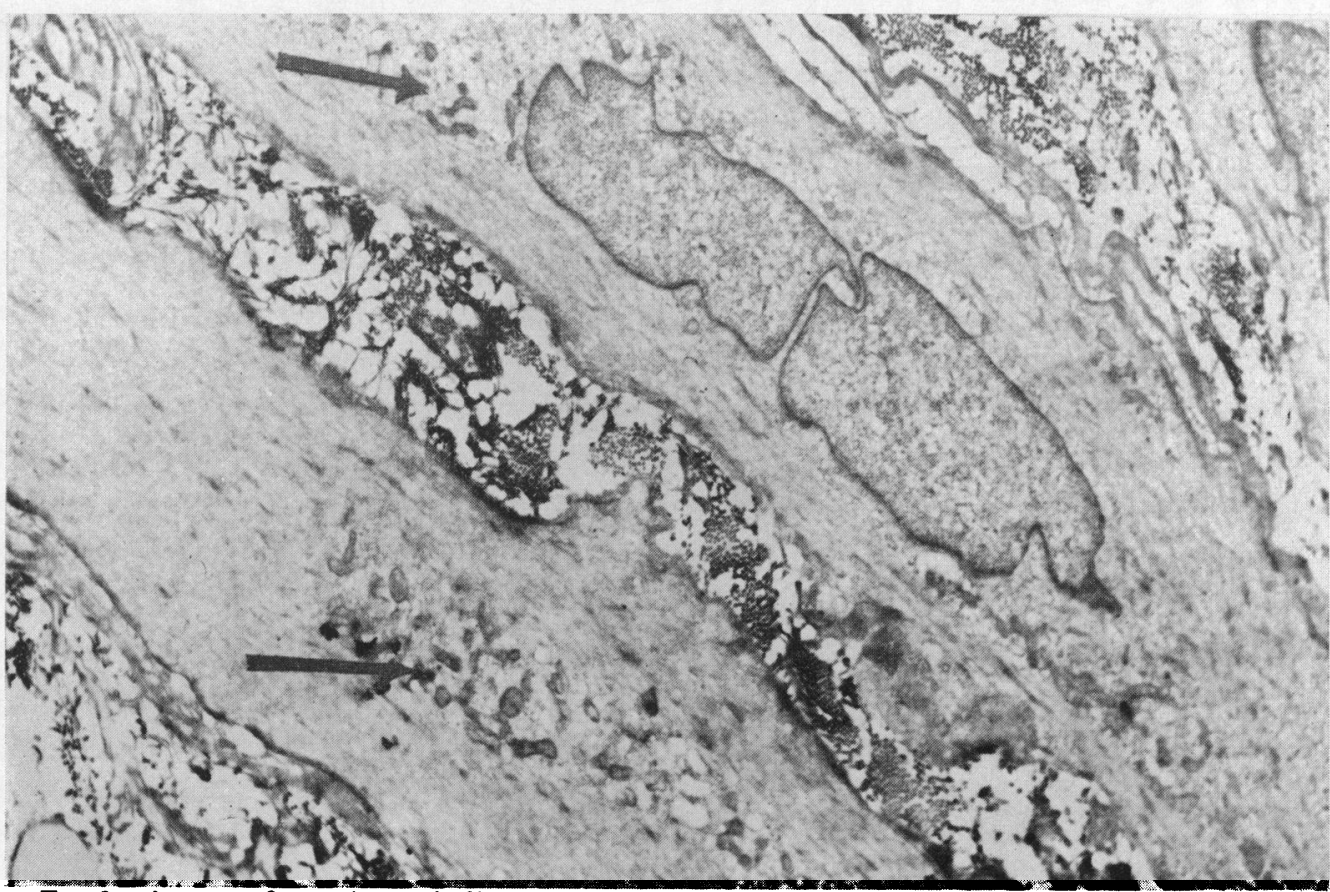

Fig. 8. - A group of smooth muscle fibres cut longitudinally. Organelles are found near the nucleus and in circumscribed areas of the cytoplasm (arrows). (Osmic-methacrylate $\times 10,000$.)

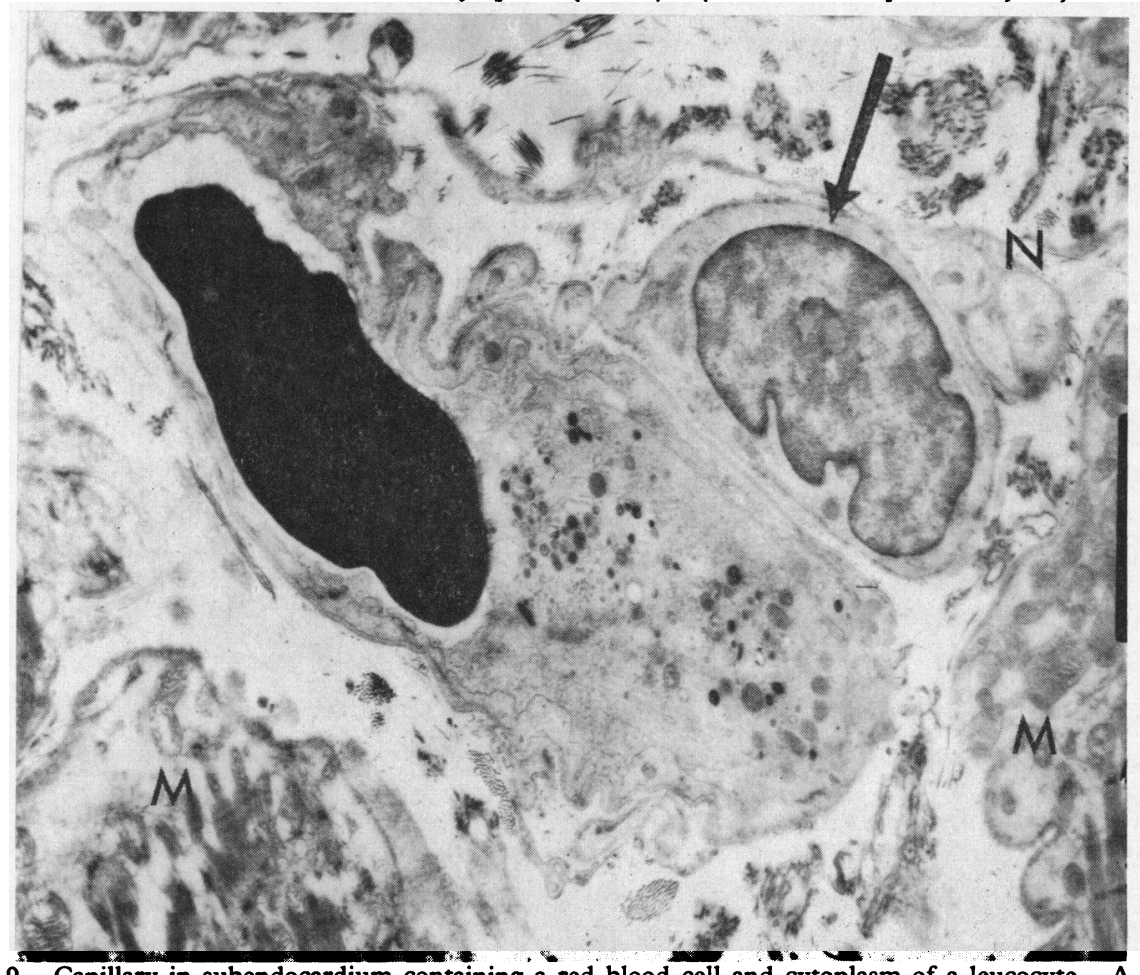

Fig. 9.-Capillary in subendocardium containing a red blood cell and cytoplasm of a leucocyte. A large pericyte (arrow) is seen and a small non-myelinated nerve fibre $(N)$ is found nearby. Portions of myocardial fibres are present $(\mathrm{M})$. (Osmic-araldite $\times 6000$.) 


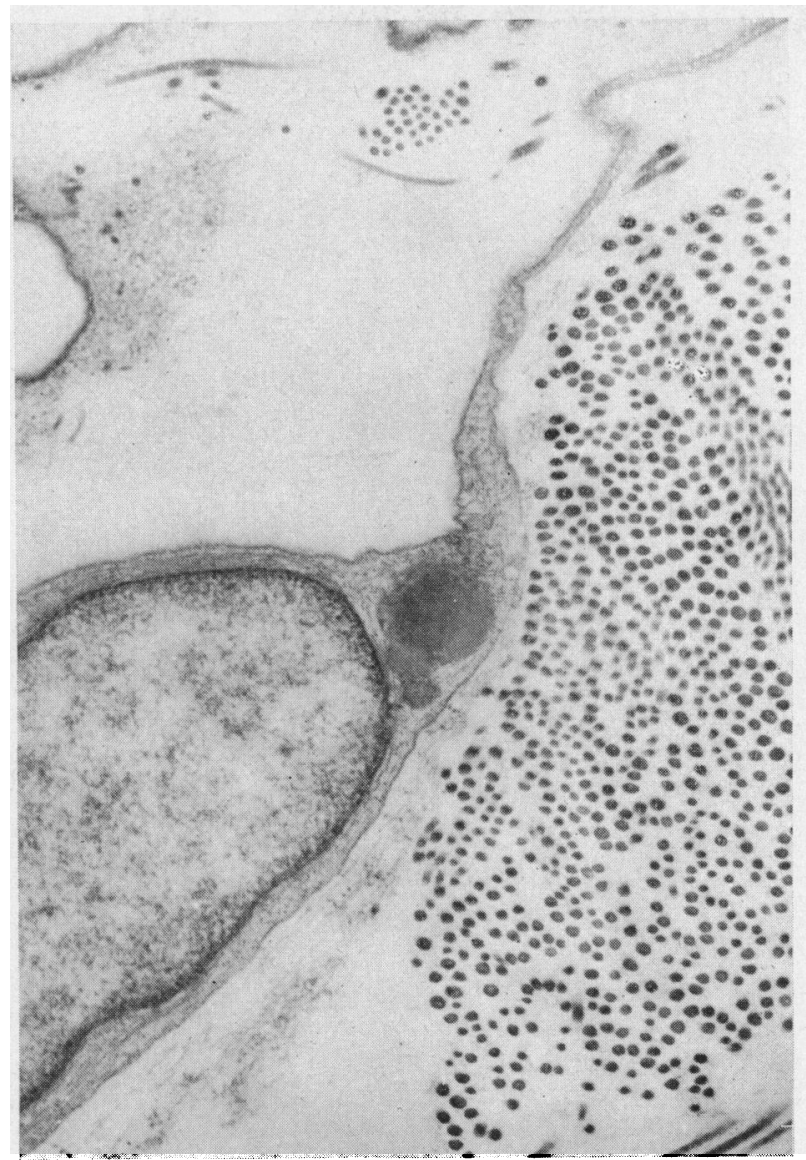

FIG. 10.-Undifferentiated cell. The cytoplasm lacks the fibrillary nature and organelles of the fibroblast, and vesicles and organelles of the macrophage. (Osmic-araldite $\times 30,000$.)

The endothelial cells are similar to those of the endocardium. Usually more than one cell lines a lumen and close cell junctions can be identified between neighbouring cells. The cells are surrounded by a basement membrane, which is fibrillary in appearance, and the pericytes by a separate basment membrane. It is not possible to differentiate lymphatic from blood capillaries.

Nerve elements. Non-myelinated nerve fibres, which are also sometimes closely related to cardiac muscle cells, are fairly common and usually accompany capillaries, particularly near the pericytes. Sometimes bare nerve axons unaccompanied by Schwann cells are seen.

Other cells. No smooth muscle cells have been identified in the subendocardium apart from those associated with metarterioles and arterioles. On the basis of morphology we have classified the cells into three types--undifferentiated cells, fibroblasts, and macrophages. The distinction between connective tissue cells is difficult on an ultra-structural basis and there is almost certainly a considerable overlap from one type to another. Undifferentiated cells are long and fusiform with little cytoplasm, which contains a few organelles, vesicles, and filaments (Fig. 10), and the nucleus is relatively flat or oval in shape.

Two types of fibroblasts can be recognized: the first has thin cell processes, frequently very long, and a generally ill-defined or interrupted cell membrane. The cytoplasm contains numerous filaments and occasional vesicles, vacuoles, and granules of various sizes. Because the cytoplasm is fibrillar and the cell membranes are ill-defined or sometimes absent, it is sometimes difficult to be certain if some areas consist of cytoplasm or of extracellular fibrillary material (Fig. 11). These cells are related to developing collagen filaments and thin collagen fibrils are often present in the vicinity, forming cytoplasmic sheets across the endocardium between collagen and elastic fibres. The second type has a more distinct cell membrane and more 


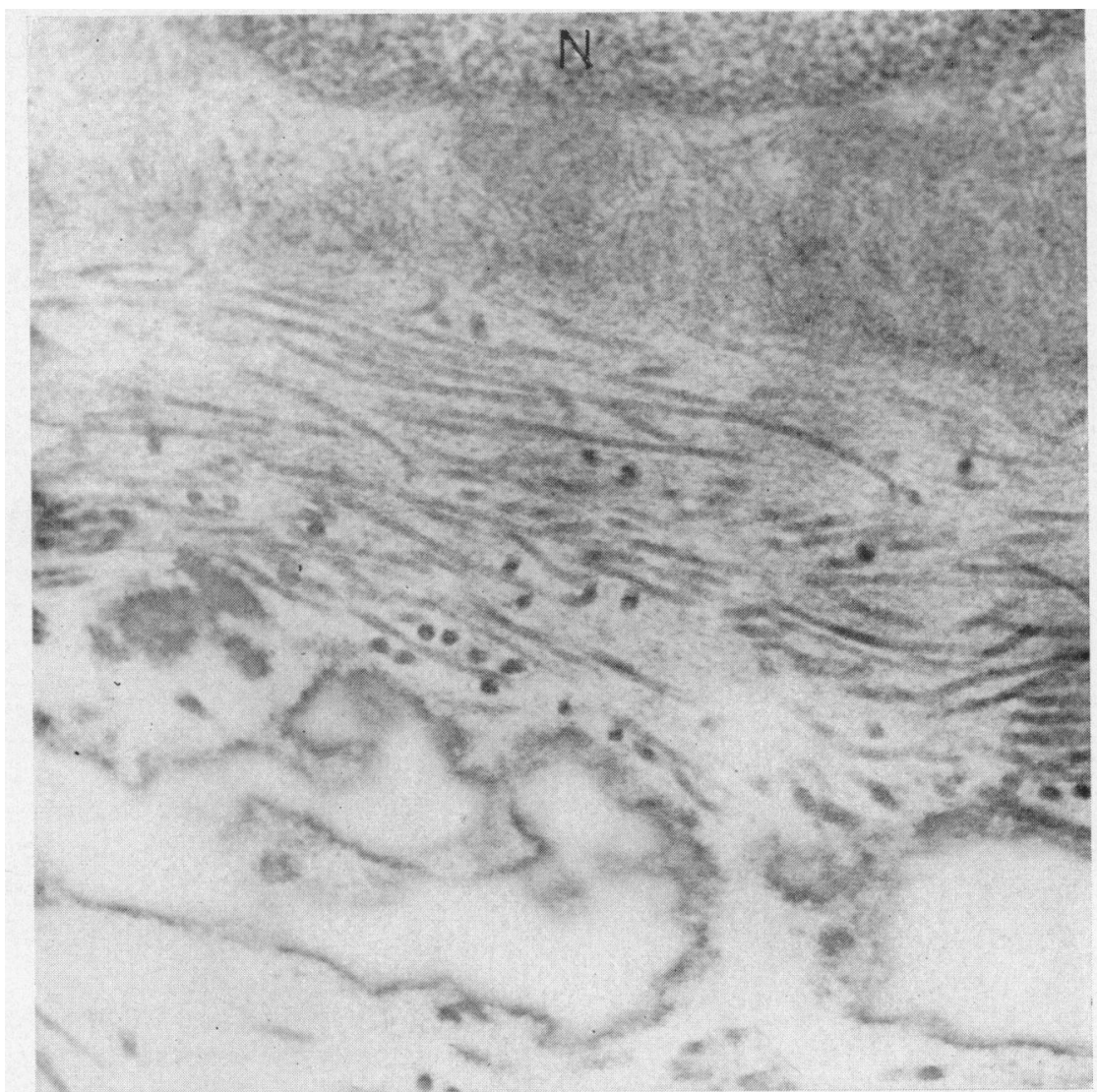

Fig. 11.-Cytoplasm of a fibroblast with part of the nucleus (N). Developing collagen filaments and thin collagen fibrils are condensed on the cell, and it is difficult to distinguish a cell membrane. (Osmic-araldite $\times 75,000$.)

cytoplasmic organelles, similar basic constituents and relation to areas of collagen fibrillogenesis (Fig. 12). The nucleus sometimes shows central chromatin condensations and the cytoplasm contains centrosomes, a variable number of tubules of rough-surfaced endoplasmic reticulum, a few mitochondria, and occasional vesicles and lipid droplets. Transitions between the two types are common and intermediate forms may show the character of one type at one side and the character of the other at the opposite side.

Macrophages are rarely seen, and resemble the second type of fibroblast, containing however more inclusions, and not related to areas of collagen fibrillogenesis (Fig. 13). There are more mitochrondria than in fibroblasts and variable numbers of rough and smooth-surfaced tubules of endoplasmic reticulum.

\section{Discussion}

Endothelial Cells. The endocardial endothelial cells are similar to other vascular endothelial cells in the subendocardium, and correspond to descriptions of endothelial cells in large arteries (Buck, 1958), small arteries (Moore and Ruska, 1957), and of capillaries (Palade, 1961; Fernando and Movat, 1964).

Collagen. Collagen fibrils vary in thickness, arrangement, and periodicity at different sites, increasing in thickness from the subendothelial layer to the subendocardium; fibre formation also increases in the same direction. The typical periodicity of collagen, 640 A.U., has not been observed, the values ranging from 400-580 A.U. It is interesting to note that variations in collagen periodicity in sections have been recorded by other authors: e.g. Chapman (1961) who gave the mean value as 500 A.U. These measurements are affected by several factors such as shrinkage during processing, compression during section cutting, errors in calibration of electron microscope magnifications, and photographic enlargements. However, the differing periodicity in different layers of the endocardium and subendocardium in a con- 


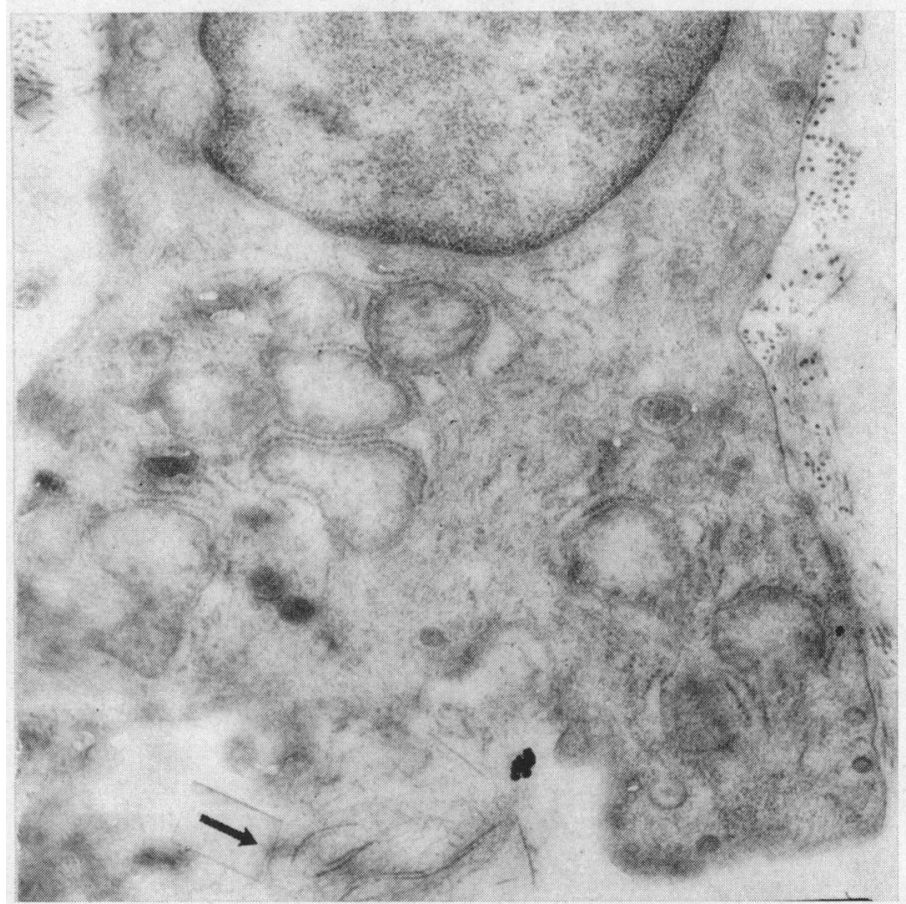

FIG. 12.-Fibroblast showing rough-surfaced tubules and mitochondria. Areas of collagen fibrillogenesis are present nearby (arrow). (Osmic-araldite $\times 18,000$.)

sistent manner is difficult to explain, since all the variables mentioned above are apparently present to the same extent.

One important feature was the difficulty encountered in measuring the periodicity in the sub- endothelial layer. Erroneous values of 220 A.U., similar to that of fibrin, are easily obtained by confusion of main bands with inter-period bands.

In addition to fibrils, which would be recognized universally as collagen fibrils, other filaments are

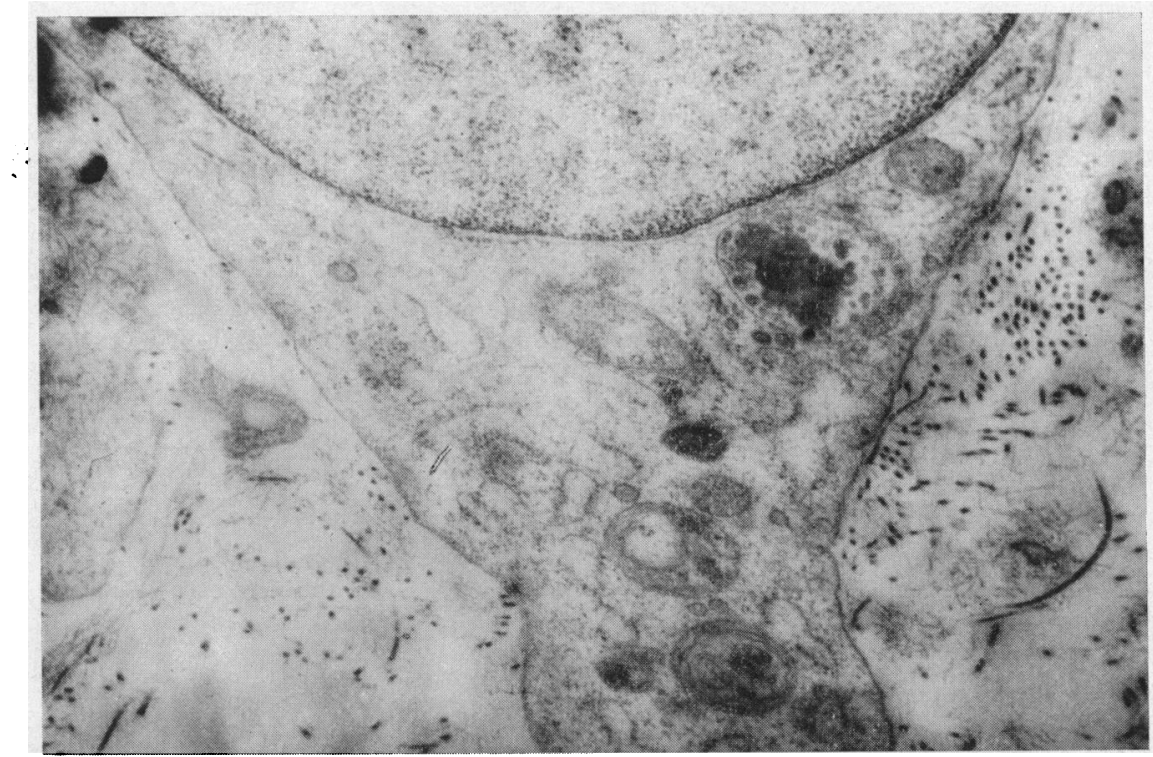

FIG. 13.-Macrophage showing various inclusions. (Osmic-araldite $\times 24,000$.) 
present, occasionally showing periodic beading and usually being found near fibroblasts; these have been considered by us to represent developing collagen filaments. Thickening into mature collagen fibrils is believed to result from aggregation of smaller longitudinal units (Gross, 1956; Porter and Pappas, 1959; Chapman, 1961).

Elastic Tissue. The increase in size and complexity of elastic fibres forms a useful guide to position in the endocardium. Although the structure of elastic tissue is poorly characterized, fibres can be recognized without difficulty, and except for occasional lines and dots in a few of the larger portions, the elastica was homogeneous in appearance, lending support to the view of Cox and Little (1961). We found no evidence of a two-component system of fibrils and amorphorous substance.

Smooth Muscle Cells. The endocardial smooth muscle cells are similar to those described in other situations. Only one type of filament is found in contrast to striated muscle (Shoenberg, 1958). Intercellular bridges have also been described (Mark, 1956; Thaemert, 1959; Harman, O’Hegarty, and Byrnes, 1962), and it has been claimed that cytoplasmic contents-except myofilaments-pass between cells at these bridges, but though we have observed these bridges, we did not note any "partial syncytium", as close cell junctions always intervened. This is in agreement with the findings of Bergman (1958).

Close contacts between nerve fibres and smooth muscle cells have also been previously described (Caesar, Edwards, and Ruska, 1957; Choi, 1963; Merrillees, Burnstock, and Holman, 1963) and some have considered these to form a type of neuromuscular junction.

Other Cells. The difficulty in distinguishing the connective tissue cells is accentuated by the fact that these cells show variable morphology. Identification becomes partly subjective, and reliance has to be placed on circumstantial evidence and on minimal limits of morphological characterization.

Fibroblasts. Fibroblasts exhibit variable morphology (Chapman, 1962; Moore and Shoenberg, 1960 ), and this variation may be related to their activity (Peach, Williams, and Chapman, 1961; Zelickson, 1963). Difficulty in distinguishing fibroblasts from histiocytes has been experienced by Chapman (1961) and from undifferentiated cells by Movat and Fernando (1962). The ill-defined cell membrane of fibroblasts in some cases may be due to the close contact of cell membrane to developing collagen filaments, a picture similar to the "marginal condensation" described by Yardley et al. (1960), but in other instances the ill-defined membrane seemed to be genuine and due to absence of the membrane at some areas. It is thought that cell wall disruption is a method by which fibroblasts shed their collagen units, among other substances, into the extracellular spaces (Chapman, 1961; Zelickson, 1963).

\section{SUMMARY}

The ultrastructure of the normal atrial endocardium is described. The endothelium is similar to other vascular endothelial cells; the subendothelial layer contains thin collagen fibrils with indistinct periodicity which may be misinterpreted as fibrin.

The elastic layer consists of collagen and elastic fibres which show variations in structure at different positions.

The subendocardium contains capillaries, metarterioles, and arterioles accompanied by nerve axons. The endocardium is avascular.

The smooth muscle cells have a structure similar to that in other situations.

The connective tissue cells are described; they consist of fibroblasts, macrophages, and undifferentiated cells. Areas of collagen fibrillogenesis have been noted and these are more frequent in the subendocardium.

We wish to thank Professor A. L. d'Abreu, Mr. L. D. Abrams, and Mr. J. L. Collis for the biopsy material. Dr. Zaki was financially supported by the British Council and the United Arab Republic. This work receives financial support from the British Heart Foundation.

\section{REFERENCES}

Becker, B. J. P. (1964). Studies on the human mural endocardium. f. Path. Bact., 88, 541.

Bergman, R. A. (1958). Intercellular bridges in ureteral smooth muscle. Bull. Fohns Hopk. Hosp., 102, 195.

Buck, R. C. (1958). The fine structure of endothelium of large arteries. f. biophys. biochem. Cytol., 4, 187.

Caesar, R., Edwards, G. A., and Ruska, H. (1957). Architecture and nerve supply of mammalian smooth muscle tissue. F. biophys. biochem. Cytol., 3, 867 .

Chapman, J. A. (1961). Morphological and chemical studies of collagen formation. 1. The fine structure of guinea pig granulomata. f. biophys. biochem. Cytol., 9, 639. (1962). Fibroblasts and collagen. Brit. med. Bull., $18,233$.

Choi, J. K. (1963). The fine structure of the urinary bladder of the toad, Bufo marinus. F. Cell. Biol., 16, 53.

Cox, R. C., and Little, K. (1961). An electron microscope study of elastic tissue. Proc. roy. Soc. $B, 155,232$.

Fernando, N. V. P., and Movat, H. Z. (1964). The fine structure of the terminal vascular bed. III. The capillaries. Exp. molec. Path., 3, 87.

Gross, J. (1956). The behavior of collagen units as a model in morphogenesis. $f$. biophys. biochem. Cytol., 2, no. 4 , pt. 2 , p. 261.

Gross, L. (1935). Lesions of the left auricle in rheumatic fever. Amer.F. Path., 11, 711. 
Harman, J. W., O'Hegarty, M. T., and Byrnes, C. K. (1962). The ultrastructure of human smooth muscle. I. Studies of cell surface and connections in normal and achalasia esophageal smooth muscle. Exp. molec. Path., $1,204$.

Koniger, H. (1903). Histologische untersuchungen über endokarditis. Arb. Path. Inst. Leipzig, 11, 2.

Lannigan, R. (1959). The rheumatic process in the left auricular appendage. F. Path. Bact., 77, 49.

Ling, L., Wang, P., and Kuo, S. (1959). Lesions of auricular appendages in rheumatic heart disease. Chin. med. F., 79, 1.

Mark, J. S. T. (1956). An electron microscope study of uterine smooth muscle. Anat. Rec., 125, 473.

Merrillees, N. C. R., Burnstock, G., and Holman, M. E. (1963). Correlation of fine structure and physiology of the innervation of smooth muscle in the guinea pig vas deferens. F. Cell. Biol., 19, 529.

Moore, D. H., and Ruska, H. (1957). The fine structure of capillaries and small arteries. $\mathcal{f}$. biophys. biochem. Cytol., 3, 457.

Moore, R. D., and Shoenberg, M. D. (1960). Studies on connective tissue. VI. The cytoplasm of the fibroblast. Exp. Cell Res., 20, 511.

Movat, H. Z., and Fernando, N. V. P. (1962). The fine structure of connective tissue. I. The fibroblast. Exp. molec. Path., 1, 509.
Nagayo, M. (1909). Zur normalen und pathologischen histologie des endocardium parietale. Beitr. path. Anat., 45, 283.

Palade, G. E. (1961). Blood capillaries of the heart and other organs. Circulation, 24, 368 .

Peach, R., Williams, G., and Chapman, J. A. (1961). A light and electron optical study of regenerating tendon. Amer. F. Path., 38, 495.

Porter, K. R., and Pappas, G. D. (1959). Collagen formation by fibroblasts of the chick embryo dermis. f. biophys. biochem. Cytol., 5, 153.

Shoenberg, C. F. (1958). An electron microscope study of smooth muscle in pregnant uterus of the rabbit. $\mathcal{F}$. biophys. biochem. Cytol., 4, 609 .

Thaemert, J. C. (1959). Intercellular bridges as protoplasmic anastomoses between smooth muscle cells. f. biophys. biochem. Cytol., 6, 67.

VonGlahn, W. C. (1926). Auricular endocarditis of rheumatic origin. Amer. F. Path., 2, 1.

Waaler, E. (1952). Activity of the rheumatic auriculitis in chronic valvular disease. Acta path. microbiol. scand., Suppl. 93, p. 211.

Yardley, J. H., Heaton, M. W., Gaines, L. M., and Shulman, L. E. (1960). Collagen formation by fibroblasts. Bull. Fohns Hopk. Hosp., 106, 381.

Zelickson, A. S. (1963). Fibroblast development and fibrogenesis. Arch. Derm., 88, 497. 